\title{
The effect of the stratospheric QBO on the neutral density of the $D$ region
}

\author{
Selçuk Sağı1 ${ }^{1}$, Ramazan Atıc1 ${ }^{2,}$, Osman Özcan ${ }^{3}$, Nurullah Yüksel ${ }^{3}$ \\ ${ }^{1}$ Mus Alparslan University, Vocational School, Department of Electronics and Otomation, Mus, Turkey \\ ${ }^{2}$ Mus Alparslan University, Faculty of Education, Mus, Turkey \\ ${ }^{3}$ Mus Alparslan University, Faculty of Arts and Sciences, Department of Physics, Mus, Turkey
}

\author{
Article history \\ Received January 18, 2014; accepted March 25, 2015. \\ Subject classification: \\ QBO, Multiple regression, Lower Ionosphere, Stratosphere.
}

\begin{abstract}
A multiple regression model, which defines relationship between two variables, is used to perform a statistical analysis of the relationship between the stratospheric $\mathrm{QBO}$ and the neutral density of the $\mathrm{D}$ region $\left(N_{n} D\right)$ at altitudes of $75 \mathrm{~km}$ and $90 \mathrm{~km}$ for Singapore station. While performing the analysis, the solar maxima and solar minima epochs of the sun for 21st, 22nd and 23rd solar cycles (SCs) are taken into account. Before applying the model for the statistical analysis of the relationship, the stationary of the variables is investigated by using the unit root test. The relationship between the variables is also investigated by using the co-integration test. The relationship between $N_{n} D$ measured at $75 \mathrm{~km}$ altitude and $\mathrm{QBO}$ obtained at altitude of $10 \mathrm{hPa}$ is observed that it is positive for solar maximum epoch at 21st and 23rd SCs and for solar minimum epoch at 21st SC and is negative at the other epochs. The relationship between $N_{n} D$ measured at $90 \mathrm{~km}$ altitude and $\mathrm{QBO}$ is observed to be negative at both the solar maxima expect for solar maximum of 23rd SC and the solar minima epochs. The relationship between variables is positive for both phases (east and west) of $\mathrm{QBO}$. Thus, $\mathrm{QBO}$ leads to a statistical change in the $N_{n} D$. It may also give rise to changes on the ion chemistry of the $D$ region.
\end{abstract}

\section{Introduction}

The region that includes the lower part of the ionosphere, at an altitude of approximately 50 to 100 kilometers, is referred to as the lower ionosphere. The D-region, that makes up a significant portion of the lower ionosphere, can be considered as a complex transition region from the neutral atmosphere to the ionosphere that are characterized by the plasma properties [Kero 2008]. One of the most important characteristics of this region is the electron density. As the rates of the chemical processes in the D-region of the ionosphere are relatively low, advection and convection significantly affect the distribution of electron density in this region [Kazimirovski and Kokoruov 1995]. Thus, the structure and composition of this region cannot be completely determined, without the clarification of the role of the atmospheric motions on all scales; particularly, its interaction with ionospheric processes, and its role in initiating the vertical transport of gas components, in the case of large scale circulation. This region is especially sensitive to meteorological influences, which may lead to variations in the electron concentration of magnitude's order. It should be noted that the normal system, which is determined by absorption of the solar radiation (both daily and annual cycles), has been perturbed sometimes by large scale waves from the troposphere [Kazimirovski and Kokoruov 1995, Krivolutsky 2009].

The Quasi-Biennial Oscillation(QBO), which is one of the meteorological effects on the D-region, is the quasi-periodic oscillation of the wind between the easterlies and the westerlies in the tropical stratosphere, with a mean period of 28 to 29 months [Heaps et al. 2000]. The QBO generally originates in the equatorial region and moves with a velocity of approximately 30 $\mathrm{m} / \mathrm{s}$ in the eastward direction and $20 \mathrm{~m} / \mathrm{s}$ in the westward direction. Even though the maximum amplitude of the $\mathrm{QBO}$ is at the level of $10 \mathrm{hPa}$, it can vary from $100 \mathrm{hPa}$ to $2 \mathrm{hPa}$. The QBO can extend up to the Mesosphere and Lower Thermosphere (MLT) beyond the stratopause with the help of waves. On reaching the mesosphere, the QBO generates a new oscillation called the Mesospheric Quasi Biennial Oscillation (MQBO) [Baldwin et al. 2001]. From this region, the QBO can extend up to the F-layer of the ionosphere, along the geomagnetic field lines of the Earth [Chen 1992]. The QBO as energy and momentum are carried by inertia-gravity waves, gravity waves, equatorial waves (Kelvin and Rossby gravity waves), and planetary waves 
from lower stratosphere to the lower ionosphere. (see Figure 1) [Baldwin et al. 2001].

In this study, the effect of $\mathrm{QBO}$ on $\mathrm{N}_{\mathrm{n}} \mathrm{D}$, is investigated statistically to determine the structure and the mixture of this region. In this context, a multiple regression is used to explore the structure of the irregularities and the underlying effects caused by QBO in $\mathrm{N}_{n} \mathrm{D}$. The relationship between $\mathrm{N}_{\mathrm{n}} \mathrm{D}$ and $\mathrm{QBO}$ is investigated by using the multiple regression model. Statistical analysis method used in the study, the results and discussion, and the conclusion are presented in Sections 2,3 and 4 .

\section{Analysis process}

A multiple regression model has three statistical parts in this study. The first one is the unit root test that analyzes the stationarity of the variables. The second one is the co-integration test that proves the relationship between the variables. The third one is the regression model that designates the value of the relationship between the variables.

In the unit root test, stationarity properties of variables are primarily examined. In order to examine the statistical relationship between the variables, the series must be stable. If the series are not stable, with the mean and the variance changing with time, then these series are made stationary by calculating the first order of difference of $\mathrm{QBO}$ and $\mathrm{N}_{\mathrm{n}} \mathrm{D}\left(\mathrm{D}(\mathrm{QBO}), \mathrm{D}\left(\mathrm{N}_{\mathrm{n}} \mathrm{D}\right)\right)$. There are three basic tests that are commonly used in the statistical studies for stationarity, namely Augmented-Dickey Fuller Test (ADF), Phillips-Perron Test (PP) and Kwiatkowski-Phillips-Schmidt-Shin Test (KPSS). ADF is widely used for investigation of the presence of the unit root in the time series. The equation including the lagged values of the dependent variable is defined by adding a constant and a time trend as follows [Enders 2008, Sagir et al. 2015]:

$$
\Delta y_{t}=\mu+\beta t+\delta y_{t-1}+\sum_{j=1}^{k} \alpha_{j} \Delta y_{t-j}+\varepsilon_{t},
$$

where $y$ is the dependent variable, $\mu$ is the mean value, $\beta$ is the coefficient of time trend, $\Delta$ is the difference processor, $t$ is the time trend, $\varepsilon$ is the error term and $k$ is the number of lags. The ADF test is based on the estimation of parameter $\delta$. If the parameter $\delta$ is different from zero, it means that the series is not stationary. If the parameter is equal to zero, it means that the series is stationary. The PP Test, which is developed to control the high degree of correlation, is a unit root test that does not include the restrictive assumptions about the error terms. In the PP test, the lagged values of the dependent value are not sufficiently included to elimi-

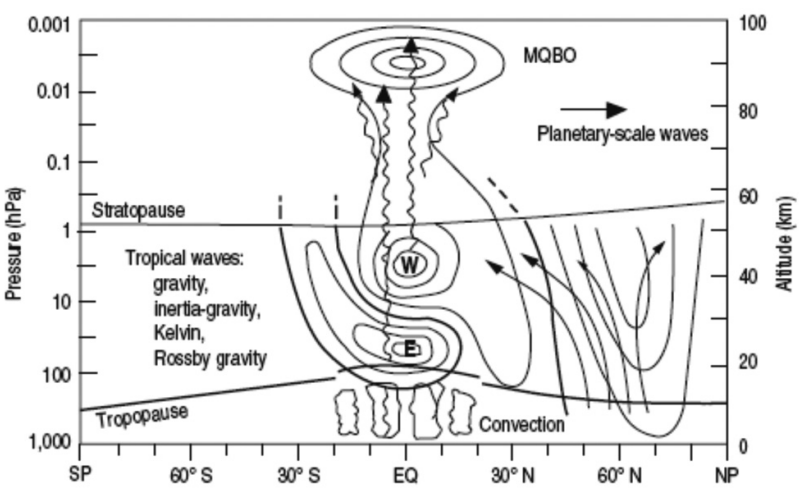

Figure 1. The atmospheric waves affecting to spread of the QBO [Mohanakumar 2008].

nate the auto-correlation in the model. Instead, it is adapted by the Newey-West estimator [Enders 2008]. The KPSS Test expresses that the series are stationary under the null hypothesis. The KPSS statistics depends on the error terms obtained from regression provided by exogenous variables of the time series [Kwiatkowski et al. 1992]. For each test, the series is proved to be stationary when the absolute value of the test values of the variables is greater than MacKinnon critical value [Enders 2008].

When two time series are not stationary and there is a stationary-linear compound in the variables, a co-integration relationship is considered. The co-integration analysis is used to estimate a relationship between the non-stationary time series. The presence of the co-integration indicates a relationship between the variables. The Engle-Granger analysis is widely used in the co-integration analysis [Engle and Granger 1987]. In the first stage of the Engle-Granger method, a relationship between the variables is estimated by the Ordinary Least Square method (OLS). After the variable coefficients are estimated by OLS, the error terms of the regression are investigated to see whether or not the series is stationary [Sagir et al. 2015].

Before performing the analysis, the QBO is considered to be the wind. The effects of the eastern (the negative sign values of $\mathrm{QBO}$ indicated by DummyE in Equation 2) and the western (the positive sign values of QBO indicated by DummyW in Equation 2) side of the wind are added to the model through dummy variables. The model is defined as follows:

$$
\begin{aligned}
& \mathrm{N}_{\mathrm{n}} \mathrm{D}_{\mathrm{t}}= \\
& \mathrm{c}+\beta_{1} \mathrm{D}\left(\mathrm{QBO}_{\mathrm{t}}\right)+\beta_{2} \text { DummyW }_{\mathrm{t}}+\beta_{3} \text { DummyE }_{\mathrm{t}}+\varepsilon_{\mathrm{t}}
\end{aligned}
$$

where, $c$ is constant and $\beta_{1}, \beta_{2}$, and $\beta_{3}$ denote coefficients of variables.

In statistical model, a dummy variable is a variable that marks or encodes a particular attribute. It is often 

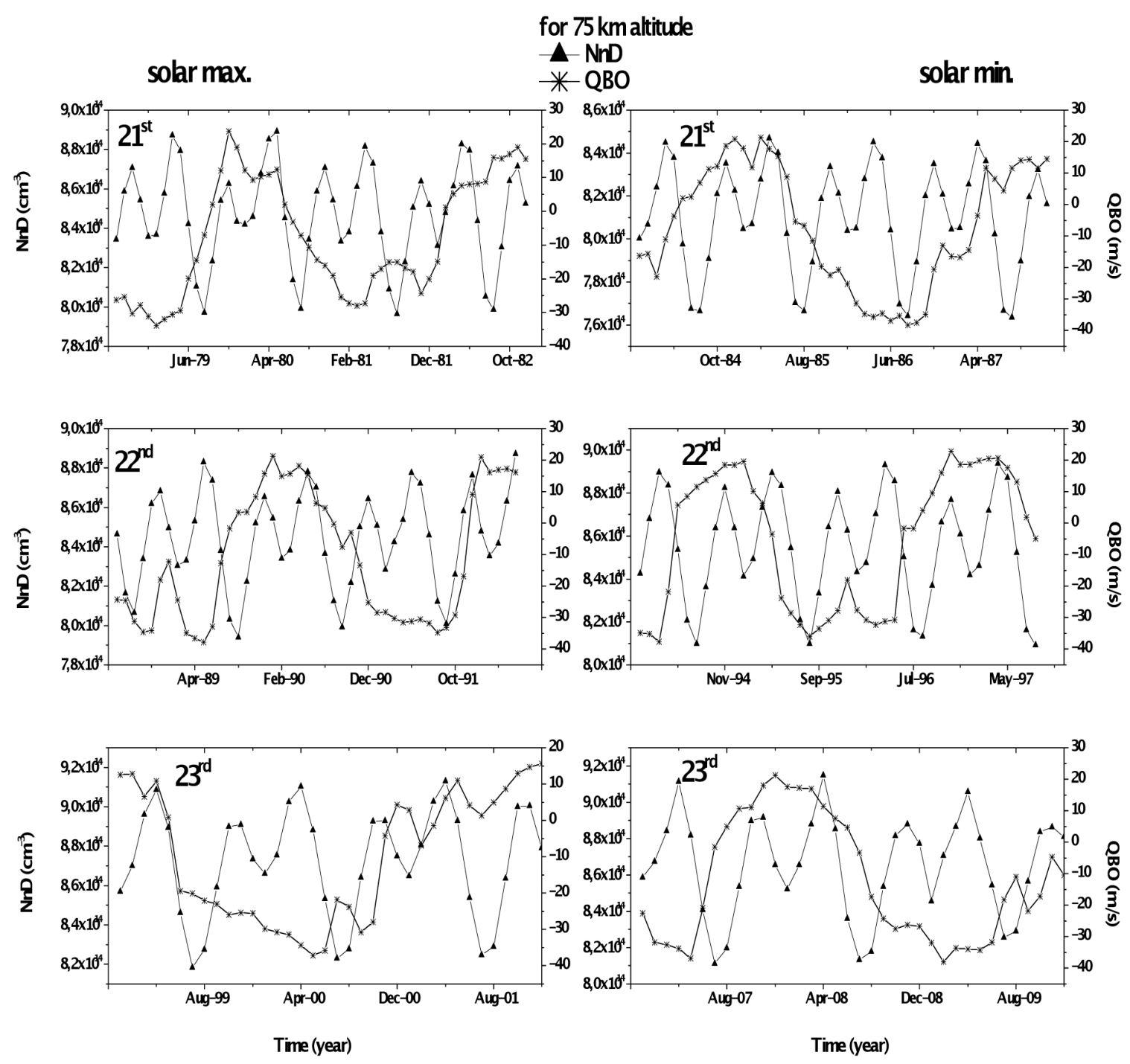

Figure 2. The variation with years of relationship between $\mathrm{QBO}$ and $\mathrm{N}_{\mathrm{n}} \mathrm{D}$ calculated at $75 \mathrm{~km}$ altitude in solar maximum (left-side) and solar minimum (right-side) epochs for 21st, 22nd and 23rd SCs.

called binary or dichotomous variable as it takes just two values, usually 1 or 0 , to indicate the presence or absence of a characteristic. Using Equation (2), the relationship between $\mathrm{QBO}$ and $\mathrm{N}_{\mathrm{n}} \mathrm{D}$ is computed for solar maxima and solar minima epochs.

\section{Results and discussion}

The QBO data used in this study are obtained from the website http:/ / strat-www.met.fu-berlin.de, from Singapore station for the geographical coordinates 01.22 N and 103.55E. The $\mathrm{N}_{\mathrm{n}} \mathrm{D}$ values are obtained monthly from the website http: / / ccmc.gsfc.nasa.gov/ modelweb/models/nrlmsise00.php for the NRLMSISE-00 atmospheric model for the same coordinates as that of the QBO data, at the local time 1200 (LT1200), and at altitudes of $75 \mathrm{~km}$ and $90 \mathrm{~km}$, respectively. Here, the $\mathrm{N}_{\mathrm{n}} \mathrm{D}$ is expressed by the sum of $\mathrm{N}_{2}, \mathrm{O}_{2}$, and $\mathrm{O}$, which are the primary components of the atmosphere.

The data used (both $\mathrm{QBO}$ and $\mathrm{N}_{\mathrm{n}} \mathrm{D}$ ) are determined so as to cover the entire month at the time interval
09/1978-12/1982, 06/1988-04/1992, 01/1999-12/2001 for solar maxima epochs and at time interval 01/198412/1987, 02/1994-08/1997, 01/2007-12/2009 for solar minima epochs (21th, 22nd and 23rd SCs). The solar minima and maxima epochs are calculated by taking the previous and next years of the year that sunspots are at lowest and highest values, respectively [Kirov et al. 2014]. The results are obtained by using given equations in Section 2 and taking reference from Enders [2008].

As a result, there is a continuing relationship between $\mathrm{QBO}$ and $\mathrm{N}_{\mathrm{n}} \mathrm{D}$. However, this relationship changes according to altitude and SCs. The results of unit root test and co-integration test are shown at the tables for 21st, 22nd, and 23rd SCs at both $75 \mathrm{~km}$ and $90 \mathrm{~km}$ altitudes.

3.1. The analysis results for $N_{n} D$ measured at an altitude of $75 \mathrm{~km}$

Figure 2 shows the variation of $\mathrm{N}_{\mathrm{n}} \mathrm{D}$ measured at $75 \mathrm{~km}$ altitude with QBO in solar maximum (left-side) and solar minimum (right-side) epochs for 21st, 22nd 
and 23rd SCs. In the solar maximum case, there is a positive relationship between $\mathrm{N}_{\mathrm{n}} \mathrm{D}$ and west-directional QBO for all three SCs.

It is observed that there is a positive relationship between $\mathrm{N}_{\mathrm{n}} \mathrm{D}$ and east-directional QBO for 21st SC. However, there is a negative relationship between variables for other SCs. In the solar minimum epoch, a positive relationship is observed between both the west-directional and east-directional $\mathrm{QBO}$ and $\mathrm{N}_{\mathrm{n}} \mathrm{D}$ for all the SCs.

\section{Unit root test results}

The purpose of the unit root test is to test the stationary nature of the variables. Because of the importance of the unit root test, it is supplemented with three separate tests (ADF, PP, and KPSS). In this test, the QBO and the $N_{n} D$ values recorded for each of the test types at the top of Table 1 need to be greater than the MacKinnon critical values or the absolute values at the bottom of the table. Table 1 tabulates the results of the unit root test between the $\mathrm{QBO}$ measured at $10 \mathrm{hPa}$ altitude and the $\mathrm{N}_{\mathrm{n}} \mathrm{D}$ obtained for $75 \mathrm{~km}$.

As shown in this table, the $\mathrm{N}_{\mathrm{n}} \mathrm{D}$ variable is significant at a level of $1 \%$ in the ADF and the KPSS tests, while it is significant at a level of $10 \%$ in the PP test. This indicates that the $\mathrm{N}_{\mathrm{n}} \mathrm{D}$ variable is stationary. However, QBO is not stationary, so it has been made stationary by taking its first difference $(\mathrm{D}(\mathrm{QBO}))$ [see Sagir et al. 2015]. $\mathrm{D}(\mathrm{QBO})$ variable is significant at a level of $5 \%$ in ADF, PP and KPSS tests.

\begin{tabular}{lccc} 
& \multicolumn{3}{c}{$\mathbf{1 0} \mathbf{~ h P a}$} \\
\cline { 2 - 4 } Variables & ADF & PP & KPSS \\
\hline QBO & -1.95 & -1.65 & 0.10 \\
$\mathbf{N}_{\mathbf{n}} \mathbf{D}$ & -5.14 & -3.32 & 0.49 \\
$\mathbf{D}(\mathrm{QBO})$ & -4.15 & -4.07 & 0.20 \\
\hline The level & MacKinnon $[\mathbf{1 9 9 6}]$ critical values \\
\cline { 2 - 4 } of significance & ADF & PP & KPSS \\
\hline $\mathbf{1 \%}$ & -4.243 & -4.243 & 0.216 \\
$\mathbf{5 \%}$ & -3.544 & -3.544 & 0.146 \\
$\mathbf{1 0} \%$ & -3.204 & -3.204 & 0.119 \\
\hline
\end{tabular}

Table 1. The unit root test results at an altitude of $75 \mathrm{~km}$.

\section{Co-integration test results}

The co-integration test results are listed in Table 2 for altitude of $75 \mathrm{~km}$ in solar maxima and solar minima epochs. Since the ADF values are greater than MacKinnon critical values as the absolute values, in case of both solar maximum $(|-4.69|>|-2.65|)$ and solar mini- mum $(|-5.94|>|-2.65|)$ there are a relationship between the $\mathrm{QBO}$ and the $\mathrm{N}_{\mathrm{n}} \mathrm{D}$. Meanwhile, since the p-values are smaller than 0.05 for both epochs (solar maximum and solar minimum), there are also a relationship at a level of $1 \%$ between the QBO and the $\mathrm{N}_{n} \mathrm{D}$. Looking at both comparisons (ADF-MacKinnon and p-values0.05 ), a relationship between the $\mathrm{QBO}$ and the $\mathrm{N}_{\mathrm{n}} \mathrm{D}$ have been observed in the $1 \%$ level of significance that is the most significant level.

\begin{tabular}{lcccc}
\multirow{2}{*}{$\begin{array}{l}\text { Regression } \\
\text { model }\end{array}$} & \multicolumn{2}{c}{ Solar maximum } & \multicolumn{2}{c}{ Solar minimum } \\
\cline { 2 - 4 } & ADF & p-value & ADF & p-value \\
\hline Model & -4.69 & 0.000 & -5.94 & 0.000 \\
\hline $\begin{array}{l}\text { The level } \\
\text { of significance }\end{array}$ & \multicolumn{3}{c}{ MacKinnon [1996] critical values } \\
\hline $\mathbf{1 \%}$ & & -2.65 & \\
$\mathbf{5 \%}$ & -1.95 & \\
$\mathbf{1 0} \%$ & & -1.61 & \\
\hline
\end{tabular}

Table 2. The co-integration test results for $75 \mathrm{~km}$.

\section{Regression analysis results}

Table 3 lists the results of the regression analysis for $\mathrm{N}_{\mathrm{n}} \mathrm{D}$ measured at an altitude of $75 \mathrm{~km}$. Ordinary Least Square (OLS) method estimates are consistent in the presence of heteroskedasticity, but the standard errors are no longer valid. The white heteroskedasticity (White Het.) Test is a test for heteroskedasticity in OLS residuals. The null hypothesis of the White Test is that there is no heteroskedasticity, and the value of this variable must also be larger than 0.05 . The Durbin-Watson Test for serial correlation assumes that is stationary and normally distributed with mean as zero. It tests the null hypothesis that the errors are uncorrelated and the values of variables need to be between 1.5 and 2.5. Probability (F-statistics) (Prob. (F-statistic)) tests the overall significance of the regression model and the value of this parameter must be smaller than 0.05 [Enders 2008, Sagir et al. 2015].

Values for the last three rows located on the bottom of the table show significance of established model and coefficients in this model. The values given in parentheses in the first five rows of the table refer to the significance of the coefficient obtained. The statistical significance of these values are shown by * sign outside the parentheses.

When the coefficients in Table 3 are investigated, it is observed that there is a negative relationship for 22nd SC in the solar maximum epoch and for 22nd and 23rd SCs in the solar minimum epoch and there is a positive relationship in other epochs. While increase of 1 meter 


\begin{tabular}{|c|c|c|c|c|c|c|}
\hline \multirow{2}{*}{ Coefficents } & \multicolumn{3}{|c|}{ Solar maximum } & \multicolumn{3}{|c|}{ Solar minimum } \\
\hline & $21 \mathrm{st}$ & 22nd & 23rd & $21 \mathrm{st}$ & 22nd & $23 \mathrm{rd}$ \\
\hline \multirow{2}{*}{ c (Constant) } & $8.41 \times 10^{20}$ & $8.25 \times 10^{20}$ & $8.70 \times 10^{20}$ & $8.10 \times 10^{20}$ & $8.45 \times 10^{20}$ & $8.63 \times 10^{20}$ \\
\hline & $(0.000)^{\star \star \star}$ & $(0.000)^{\star \star \star}$ & $(0.000)^{\star \star \star}$ & $(0.000)^{\star \star \star}$ & $(0.000)^{\star \star \star}$ & $(0.000)^{\star \star \star}$ \\
\hline \multirow{2}{*}{$\beta_{1} \mathrm{D}(\mathrm{QBO})$} & $6.13 \times 10^{17}$ & $-5.0 \times 10^{17}$ & $5.70 \times 10^{17}$ & $8.68 \times 10^{17}$ & $-3.63 \times 10^{17}$ & $-6.19 \times 10^{17}$ \\
\hline & $(0.015)^{\star \star}$ & $(0.022)^{\star \star}$ & $(0.009)^{\star \star \star}$ & $(0.004)^{\star \star \star}$ & $(0.010)^{\star \star \star}$ & $(0.040)^{\star \star}$ \\
\hline \multirow{2}{*}{$\boldsymbol{\beta}_{2}($ DummyW $)$} & $8.54 \times 10^{20}$ & $8.52 \times 10^{20}$ & $8.73 \times 10^{20}$ & $8.11 \times 10^{20}$ & $8.44 \times 10^{20}$ & $8.70 \times 10^{20}$ \\
\hline & $(0.000)^{\star \star \star}$ & $(0.000)^{\star \star \star}$ & $(0.000)^{\star \star \star}$ & $(0.000)^{\star \star \star}$ & $(0.000)^{\star \star \star}$ & $(0.000)^{\star \star \star}$ \\
\hline \multirow{2}{*}{$\beta_{3}$ (DummyE) } & $8.41 \times 10^{20}$ & $8.25 \times 10^{20}$ & $8.70 \times 10^{20}$ & $8.10 \times 10^{20}$ & $8.45 \times 10^{20}$ & $8.63 \times 10^{20}$ \\
\hline & $(0.000)^{\star \star \star}$ & $(0.000)^{\star \star \star}$ & $(0.000)^{\star \star \star}$ & $(0.000)^{\star \star \star}$ & $(0.000)^{\star \star \star}$ & $(0.000)^{\star \star \star}$ \\
\hline \multirow{2}{*}{$\operatorname{AR}(1)$} & 0.113 & 0.998 & 1.47 & 0.385 & 1.001 & 1.052 \\
\hline & $(0.555)$ & $(0.000)^{\star \star \star}$ & $(0.000)^{\star \star \star}$ & $(0.024)^{\star \star}$ & $(0.000)^{\star \star \star}$ & $(0.000)^{\star \star \star}$ \\
\hline $\mathrm{R}^{2}$ & 0.82 & 0.77 & 0.86 & 0.72 & 0.85 & 0.84 \\
\hline Adj. $R^{2}$ & 0.79 & 0.74 & 0.84 & 0.68 & 0.82 & 0.81 \\
\hline Durbin Watson & 1.851 & 1.991 & 2.027 & 1.602 & 2.011 & 1.923 \\
\hline Prob. (F-statistics) & $(0.000)$ & $(0.000)$ & $(0.000)$ & $(0.000)$ & $(0.000)$ & $(0.000)$ \\
\hline White Het. & $(0.611)$ & $(0.116)$ & $(0.945)$ & $(0.305)$ & $(0.688)$ & $(0.094)$ \\
\hline
\end{tabular}

Table 3. The regression model results for $75 \mathrm{~km}$ altitude. $\left({ }^{\star}\right),\left({ }^{\star \star}\right),\left(^{\star \star \star}\right)$ represents the significant level at $1 \%, 5 \%$, and $10 \%$, respectively.

per second of QBO in the solar maxima epochs for 21st and 23rd SCs causes an increase of $6.13 \times 10^{17} \mathrm{~m}^{-3}$ and $5.7 \times 10^{17} \mathrm{~m}^{-3}$, it causes a decrease of $5.0 \times 10^{17} \mathrm{~m}^{-3}$ in 22nd SC. Whereas increase of 1 meter per second of QBO in the solar minima epochs for 22nd and 23rd SCs causes a decrease of $3.63 \times 10^{17} \mathrm{~m}^{-3}$ and $6.19 \times 10^{17} \mathrm{~m}^{-3}$, it causes an increase of $8.68 \times 10^{17} \mathrm{~m}^{-3}$ in $21 \mathrm{st} \mathrm{SC}$. The correlation coefficient $\left(\mathrm{R}^{2}\right)$ in the analysis carried out with the whole set of the QBO is higher than those Danilov [1998] who investigates relationship between $\mathrm{QBO}$ and electron density.

It is observed that $\beta_{2}$ (DummyW) and $\beta_{3}$ (DummyE) coefficients indicating wind direction are having positive effect on $\mathrm{N}_{\mathrm{n}} \mathrm{D}$ in both solar maxima and solar minima epochs. This positive relationship can be associated with carrying positive/negative ions and neutral particles upward of QBO through waves abovementioned based on sentence expressed by Lastovicka [2006] "The meteorological influences play an important role in the overall ionospheric variability [e.g., Forbes et al. 2000, Rishbeth and Mendillo 2001]". This results obtained are fully consistent with Danilov [1998] for $\beta_{2}$ coefficient, while $\beta_{3}$ coefficient are partly consistent with Danilov [1998]. The impact rate of these coefficients is close to each other. Although Adj. $\mathrm{R}^{2}$ value varies with the solar cycle, it is expressed that about $68 \%-84 \%$ of changes in $\mathrm{N}_{\mathrm{n}} \mathrm{D}$ according to this model can be explained by QBO. The remaining portion (approximately $32 \%$ $16 \%$ ) can be explained by the other effects which are not including to model here (such as, lightning, earthquakes, tides) of sub-atmospheric origin. The results obtained are supported that the ion-generation processes that occur in the lower ionosphere are closely related to the chemistry of neutral components and to meteorological processes [Krivolutsky 2009].

3.2. The analysis results for $N_{n} D$ measured at an altitude of $90 \mathrm{~km}$

Figure 3 shows the variation of $\mathrm{N}_{\mathrm{n}} \mathrm{D}$ calculated at $90 \mathrm{~km}$ altitude with QBO in the solar maximum (leftside) and solar minimum (right-side) epochs for 21st, 22nd and 23rd SCs. In the solar maximum epoch, there is a positive relationship between $\mathrm{N}_{\mathrm{n}} \mathrm{D}$ and west-directional QBO for all three SCs. While there is a positive relationship between $\mathrm{N}_{\mathrm{n}} \mathrm{D}$ and east-directional $\mathrm{QBO}$ for $21 \mathrm{st} \mathrm{SC}$, a negative relationship is observed for $22 \mathrm{nd}$ and 23rd SCs. In the solar minimum epoch, there is a positive relationship between $\mathrm{N}_{\mathrm{n}} \mathrm{D}$ and west-directional QBO for all three SCs. While there is a negative relationship between $\mathrm{N}_{\mathrm{n}} \mathrm{D}$ and east-directional $\mathrm{QBO}$ in 23rd SC, a positive relationship is observed in 21st and 22nd SCs.

\section{Unit root test results}

Table 4 lists the results of the unit root test of the $\mathrm{QBO}$ and $\mathrm{N}_{\mathrm{n}} \mathrm{D}$ variables, measured at $10 \mathrm{hPa}$ and at an altitude of $75 \mathrm{~km}$, respectively. It can be seen that the variables are not stationary for all the three 


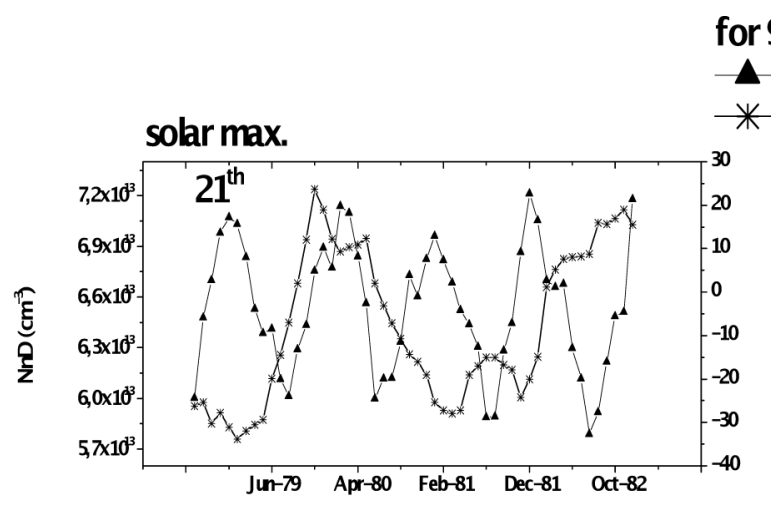

for $90 \mathrm{~km}$ altitude

$\triangle \mathrm{NnD}$

* QBO

solar min
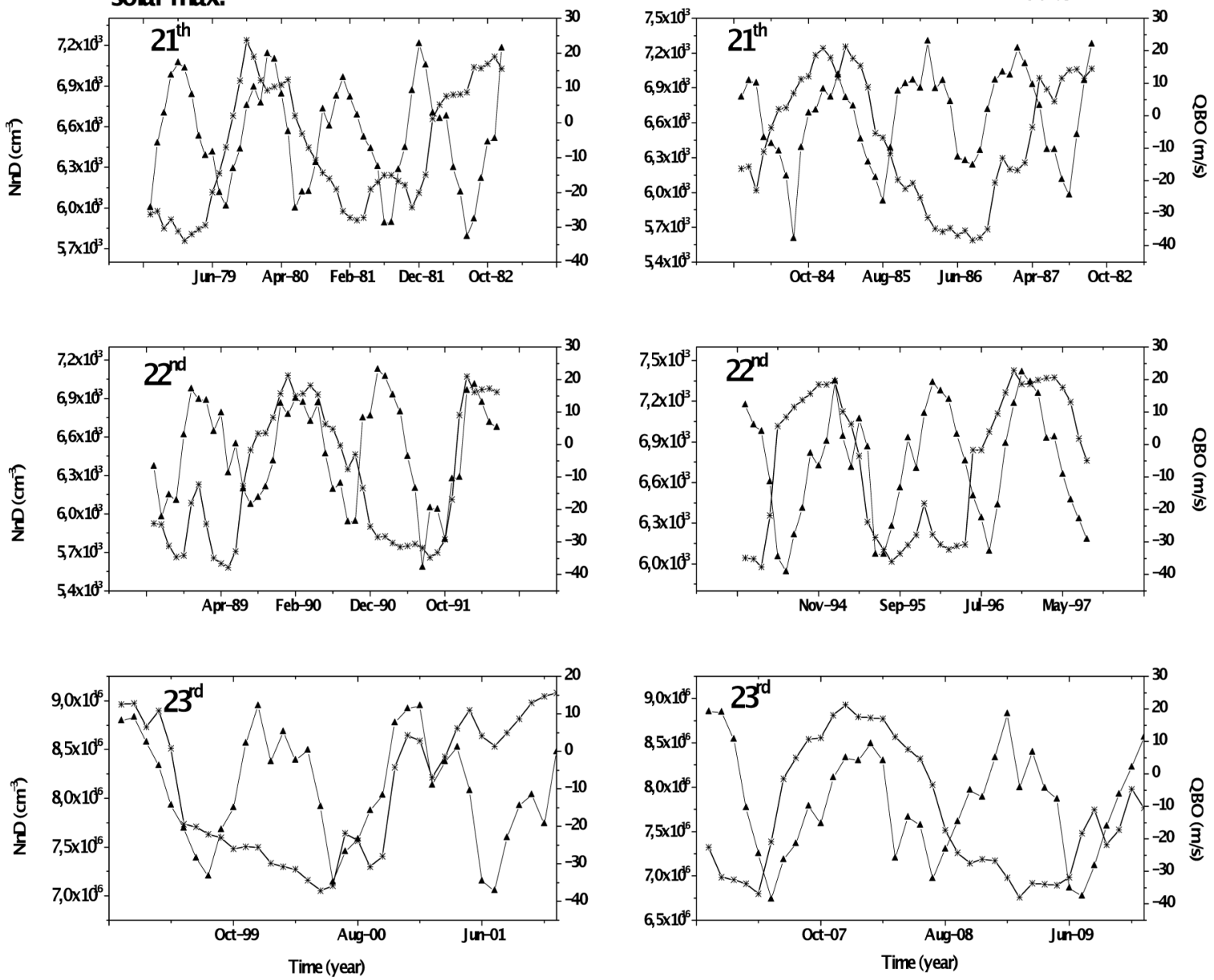

Figure 3. The variation with years of relationship between $\mathrm{QBO}$ and $\mathrm{N}_{\mathrm{n}} \mathrm{D}$ calculated at $90 \mathrm{~km}$ altitude in solar maximum (left-side) and solar minimum (right-side) epochs for 21st, 22nd and 23rd SCs.

tests. In order to make the variable stationary, their first differences $\left(\mathrm{D}(\mathrm{QBO}), \mathrm{D}\left(\mathrm{N}_{\mathrm{n}} \mathrm{D}\right)\right.$ ) were considered. As a result, the variable $\mathrm{D}(\mathrm{QBO})$ is statistically significant at $1 \%$ in the ADF and PP tests, while it is statis-

\begin{tabular}{lccc} 
& \multicolumn{3}{c}{$\mathbf{1 0} \mathbf{h P a}$} \\
\cline { 2 - 4 } Variables & ADF & PP & KPSS \\
\hline QBO & -2.63 & -2.63 & 0.078 \\
$\mathbf{N}_{\mathbf{n}} \mathbf{D}$ & -7.22 & -3.65 & 0.040 \\
$\mathbf{D}(\mathbf{Q B O})$ & -7.36 & -7.36 & 0.084 \\
$\mathbf{D}\left(\mathbf{N}_{\mathbf{n}} \mathbf{D}\right)$ & -5.30 & -4.50 & 0.080 \\
\hline
\end{tabular}

\begin{tabular}{lccc}
\hline \multirow{2}{*}{$\begin{array}{l}\text { The level } \\
\text { of significance }\end{array}$} & \multicolumn{3}{c}{ MacKinnon [1996] critical values } \\
\cline { 2 - 4 } & ADF & PP & KPSS \\
\hline $\mathbf{1 \%}$ & -4.243 & -4.243 & 0.216 \\
$\mathbf{5 \%}$ & -3.544 & -3.544 & 0.146 \\
$\mathbf{1 0} \%$ & -3.204 & -3.204 & 0.119 \\
\hline
\end{tabular}

Table 4. The unit root test results for $90 \mathrm{~km}$. tically insignificant in the KPSS test. The variable $\mathrm{NnD}$ is the same as the variable QBO. Thanks to the variables $\mathrm{D}(\mathrm{QBO})$ and $\mathrm{D}\left(\mathrm{N}_{\mathrm{n}} \mathrm{D}\right)$ are significant according to two tests (ADF and PP), they are considered to be stationary.

\section{Co-integration test results}

In Table 5, the results of the co-integration test for $\mathrm{N}_{\mathrm{n}} \mathrm{D}$ measured at an altitude of $90 \mathrm{~km}$ for solar maximum and the solar minimum epochs are listed. Since the ADF values are greater than MacKinnon critical values as the absolute values, in both solar maximum $(|-4.24|>|-2.65|)$ and solar minimum epochs $(|-5.71|>$ $|-2.65|)$ there are a relationship between the $\mathrm{QBO}$ and the $\mathrm{N}_{\mathrm{n}} \mathrm{D}$. Meanwhile, since the $\mathrm{p}$-values are also smaller than 0.05 for both cycles (solar maximum and solar minimum), there is relationship between the $\mathrm{QBO}$ and the $\mathrm{N}_{\mathrm{n}} \mathrm{D}$. Looking at both comparisons (ADF-MacKinnon and p-values-0.05), a relationship between the $\mathrm{QBO}$ and the $\mathrm{N}_{\mathrm{n}} \mathrm{D}$ has been observed in the $1 \%$ level of significance that is the most significant level. 
Regression analysis results

The regression analysis results for $\mathrm{N}_{\mathrm{n}} \mathrm{D}$, measured at an altitude of $90 \mathrm{~km}$, are listed in Table 6 . If the resultant value is smaller than the Probability (F-statistic) (Prob. (F-statistic)) value of 0.05 , it indicates that the developed model is significant. It is observed that $\beta_{2}$ and $\beta_{3}$ coefficients indicating wind direction are having positive effect on $\mathrm{N}_{\mathrm{n}} \mathrm{D}$ and this effect is very close to each other in 21 st and 22nd SCs. Such as $\beta_{1}$ coefficient, it is observed that effect on $N_{n} D$ of $\beta_{2}$ and $\beta_{3}$ coefficients is also higher in the 23rd SC than 21st and 22nd SCs. Although Adj. $\mathrm{R}^{2}$ value varies with the SC, changes of about $50 \%-75 \%$ in $\mathrm{N}_{\mathrm{n}} \mathrm{D}$ can be explained by QBO. This result shows that QBO can disturb to lower ionosphere via troposphere based waves as expressed to introduction [Kazimirovski and Kokoruov 1995, Krivolutsky 2009]. According to the coefficients in Table 6, it is observed that there is only a positive relationship in the solar maximum epoch for $23 \mathrm{rd}$ SC and there is a negative relationship for all remaining cases. Change of 1 meter per second in QBO ( $\beta_{1}$ coefficient in the Table 6) in both solar maximum and solar minimum epochs for 21 st and 22nd SCs gives rise to a decrease of about $1.36 \times$ $10^{16} \mathrm{~m}^{-3}-13 \times 10^{16} \mathrm{~m}^{-3}$. However, this change in the $23 \mathrm{rd}$ SC causes an increase of $2.32 \times 10^{20} \mathrm{~m}^{-3}$ in solar maximum epoch and brings about a decrease of $1.98 \times$ $10^{16} \mathrm{~m}^{-3}$ for solar minimum epoch.

Values for the last three lines located on the bottom of the table show significance of established model

\begin{tabular}{lcccc}
\multirow{2}{*}{$\begin{array}{l}\text { Regression } \\
\text { model }\end{array}$} & \multicolumn{2}{c}{ Solar maximum } & \multicolumn{2}{c}{ Solar minimum } \\
\cline { 2 - 4 } & ADF & p-value & ADF & p-value \\
\hline Model & -4.24 & 0.0001 & -5.71 & 0.000 \\
\hline $\begin{array}{l}\text { The level } \\
\text { of significance }\end{array}$ & \multicolumn{3}{c}{ Mackinnon [1996] critical values } \\
\hline $\mathbf{1 \%}$ & & -2.65 & \\
$\mathbf{5 \%}$ & & -1.95 & \\
$\mathbf{1 0} \%$ & & -1.61 & \\
\hline
\end{tabular}

Table 5. The co-integration test results for $90 \mathrm{~km}$.

and coefficients in this model. The values given in parentheses in the first five lines of the table refer to the significance of the coefficient obtained. The statistical significance of these values are shown by ${ }^{\star}$ sign outside the parentheses.

When results obtained for both altitudes $(75 \mathrm{~km}$ and $90 \mathrm{~km}$ ) are compared, as expected, it is found that occurring change in $\mathrm{N}_{\mathrm{n}} \mathrm{D}$ by $\mathrm{QBO}$ is higher about 10 times at $75 \mathrm{~km}$ altitude than $90 \mathrm{~km}$ altitude in $21 \mathrm{st}$ and 22nd SCs. But, this change is higher about 1000 times at $90 \mathrm{~km}$ altitude than $75 \mathrm{~km}$ altitude in 23rd SC.

\section{Conclusion}

In this study, the underlying effects and the changes in the $\mathrm{N}_{\mathrm{n}} \mathrm{D}$ caused by the stratospheric QBO are investigated using a multiple regression model. Also, both the solar maxima and the solar minima epochs are taken into

\begin{tabular}{|c|c|c|c|c|c|c|}
\hline \multirow{2}{*}{ Coefficents } & \multicolumn{3}{|c|}{ Solar maximum } & \multicolumn{3}{|c|}{ Solar minimum } \\
\hline & $21 s t$ & 22nd & 23 rd & $21 \mathrm{st}$ & 22nd & $23 \mathrm{rd}$ \\
\hline \multirow{2}{*}{ c (Constant) } & $6.54 \times 10^{19}$ & $6.49 \times 10^{19}$ & $8.22 \times 10^{22}$ & $6.80 \times 10^{19}$ & $6.62 \times 10^{19}$ & $7.67 \times 10^{22}$ \\
\hline & $(0.000)^{\star \star \star}$ & $(0.000)^{\star \star \star}$ & $(0.000)^{\star \star \star}$ & $(0.000)^{\star \star \star}$ & $(0.002)^{\star \star \star}$ & $(0.000)^{\star \star \star}$ \\
\hline \multirow{2}{*}{$\beta_{1} \mathrm{D}(\mathrm{QBO})$} & $-9.75 \times 10^{16}$ & $-1.36 \times 10^{16}$ & $2.32 \times 10^{20}$ & $-1.30 \times 10^{17}$ & $-8.58 \times 10^{16}$ & $-1.98 \times 10^{16}$ \\
\hline & $(0.075)^{\star}$ & $(0.031)^{\star \star}$ & $(0.011)^{\star \star}$ & $(0.065)^{\star}$ & $(0.055)^{\star}$ & $(0.018)^{\star \star}$ \\
\hline \multirow{2}{*}{$\boldsymbol{\beta}_{2}$ (DummyW) } & $6.56 \times 10^{19}$ & $6.74 \times 10^{19}$ & $8.36 \times 10^{22}$ & $6.67 \times 10^{19}$ & $6.62 \times 10^{19}$ & $7.89 \times 10^{22}$ \\
\hline & $(0.000)^{\star \star \star}$ & $(0.000)^{\star \star \star}$ & $(0.000)^{\star \star \star}$ & $(0.000)^{\star \star \star}$ & $(0.000)^{\star \star \star}$ & $(0.000)^{\star \star \star}$ \\
\hline \multirow{2}{*}{$\beta_{3}($ DummyE) } & $6.54 \times 10^{19}$ & $6.49 \times 10^{19}$ & $8.22 \times 10^{22}$ & $6.80 \times 10^{19}$ & $6.62 \times 10^{19}$ & $7.67 \times 10^{22}$ \\
\hline & $(0.000)^{\star \star \star}$ & $(0.000)^{\star \star \star}$ & $(0.000)^{\star \star \star}$ & $(0.000)^{\star \star \star}$ & $(0.000)^{\star \star \star}$ & $(0.000)^{\star \star \star}$ \\
\hline \multirow{2}{*}{$\operatorname{AR}(1)$} & 1.635 & 0.523 & 0.495 & 0.815 & 0.557 & 0.543 \\
\hline & $(0.000)^{\star \star \star}$ & $(0.003)^{\star \star \star}$ & $(0.032)^{\star \star}$ & $(0.003)^{\star \star \star}$ & $(0.003)^{\star \star \star}$ & $(0.000)^{\star \star \star}$ \\
\hline $\mathbf{R}^{2}$ & 0.78 & 0.67 & 0.58 & 0.59 & 0.63 & 0.67 \\
\hline $\operatorname{Adj} . R^{2}$ & 0.75 & 0.56 & 0.50 & 0.51 & 0.58 & 0.61 \\
\hline Durbin Watson & 2.143 & 2.059 & 1.823 & 1.997 & 1.970 & 2.030 \\
\hline Prob. (F-statistics) & $(0.000)$ & $(0.000)$ & $(0.000)$ & $(0.000)$ & $(0.000)$ & $(0.000)$ \\
\hline White Het. & $(0.243)$ & $(0.670)$ & $(0.356)$ & $(0.919)$ & $(0.568)$ & $(0.509)$ \\
\hline
\end{tabular}

Table 6. The regression model results for $90 \mathrm{~km} .\left(^{\star}\right),\left({ }^{\star \star}\right),\left({ }^{\star \star \star}\right)$ represents the significant level at $1 \%, 5 \%$, and $10 \%$, respectively. 
consideration at the evaluating of the relationship between variables. The results are as follows:

- The explainable rate is higher at $75 \mathrm{~km}$ altitude than at $90 \mathrm{~km}$ altitude.

- The explainable rate of the effect on the $\mathrm{N}_{\mathrm{n}} \mathrm{D}$ of QBO is $79 \%, 74 \%$ and $84 \%$ and $68 \%, 82 \%$ and $81 \%$ in the solar maxima and the solar minima epochs for 21st, 22nd and 23rd SCs at $75 \mathrm{~km}$ altitude, respectively.

- The explainable rate of the effect on the $\mathrm{N}_{\mathrm{n}} \mathrm{D}$ of QBO is $75 \%, 56 \%$ and $50 \%$ and $51 \%, 58 \%$ and $61 \%$ in the solar maxima and the solar minima epochs for $21 \mathrm{st}$, 22nd and 23rd SCs at $90 \mathrm{~km}$ altitude, respectively.

- The relationship between variables is positive for both direction of $\mathrm{QBO}$ at both altitudes.

- The relationship between $\mathrm{QBO}$ and $\mathrm{N}_{\mathrm{n}} \mathrm{D}$ is positive for 21st and 23rd SCs in solar minimum epoch and for 21st SC in solar maximum epoch at $75 \mathrm{~km}$ altitude. In the remaining cases, relationship between variables is negative.

- While the relationship between $\mathrm{QBO}$ and $\mathrm{N}_{\mathrm{n}} \mathrm{D}$ is positive for 23rd SC in solar minimum epoch, it is negative in the remaining cases at $90 \mathrm{~km}$ altitude.

It is noted that, none of these statistical studies provides any physical mechanism to determine the apparent relationships, but the QBO through the atmospheric waves [Pancheva et al. 1991] may have a greater effect on the $\mathrm{N}_{\mathrm{n}} \mathrm{D}$ in the D-region, which is considered as weakly ionized plasma. Apart from causing a statistical decrease in the $\mathrm{N}_{\mathrm{n}} \mathrm{D}$ due to the QBO, it is also may give rise to changes in the ion chemistry of this region [Krivolutsky 2009]. This change would become physically and chemically by interacting with the carrying momentum by QBO of neutral components in D-region. Thus, neutrals turn into ions by means of collisions and various chemical reactions or vice versa, and $\mathrm{N}_{\mathrm{n}} \mathrm{D}$ number may be changed. Thus, $\mathrm{QBO}$, that is one of the meteorological influences, can play an important role in the lower ionospheric $\mathrm{N}_{\mathrm{n}} \mathrm{D}$.

\section{References}

Baldwin, M., L. Gray, T. Dunkerton, K. Hamilton, P. Haynes, W. Randel, J. Holton, M. Alexander, I. Hirota and T. Horinouchi (2001). The quasi-biennial oscillation, Rev. Geophys., 39 (2), 179-229.

Chen, P.R. (1992). Evidence of the ionospheric response to the QBO, Geophys. Res. Lett., 19 (11), 1089-1092.

Danilov, A.D. (1998). Solar activity effects in the ionospheric D region, Ann. Geophysicae, 1527-1533.

Enders, W. (2008). Applied Econometric Time Series, John Wiley \& Sons.

Engle, R.F., and C.W.J. Granger (1987). Co-integration and error correction: Representation, estimation and testing, Econometrica, 55, 251-276.
Forbes, J.M., S.E. Palo and X. Zhang (2000). Variability of the ionosphere, J. Atmos. Terr. Phys., 62 (8), 685693.

Heaps, A., W. Lahoz and A. O’Neill (2000).The QuasiBiennial zonal wind Oscillation (QBO), Centre for Global Atmospheric Modelling, Department of Meteorology, University of Reading, UK.

Kazimirovsky, E.S., and V.D. Kokourov (1995). Meteorological effects in the ionosphere: A review, Geomagn. Aeron., 35 (3), 303-320.

Kirov, B., S. Asenovski, K. Georgieva and V.N. Obridko (2014). What causes geomagnetic activity during sunspot minimum?, Solar and Solar-Terrestrial Physics, Saint Petersburg, Pulkovo, October 20-24, 219-222.

Kero, A. (2008). Ionospheric D-region Studies by Means of Active Heating Experiments and Modelling, Sodankylä Geophysical Observatory Publications No. 102, Oulu University Press, Finland.

Krivolutsky, A.A. (2009). Russian studies of the middle atmosphere in 2003-2006, Izvestiya, Atmos-Oceanic Phys., 45 (4), 528-539.

Kwiatkowski, D., P.C.B. Phillips, P. Schmidt and Y. Shin (1992). Testing the null hypothesis of stationary against the alternative of a unit root: How sure are we that economic time series have a unit root?, J. Econometrics, 54 (1), 159-178.

Lastovicka, J. (2006). Forcing of the ionosphere by waves from below, J. Atmos. Terr. Phys., 68 (3-5), 479-497.

MacKinnon, J.G. (1996). Numerical distribution functions for unit root and cointegration tests, J. App. Econometrics, 11, 601-618.

Mohanakumar, K. (2008). Stratosphere Troposphere Interaction, Springer Doc. Goghin.

Pancheva, D., J. Lastovicka, B.A. de la Morena (1991). Quasi-periodic fluctuations in ionospheric absorption in relation to planetary activity in the stratosphere, J. Atmos. Terr. Phys., 53, 1151-1156.

Rishbeth, H., and M. Mendillo (2001). Patterns of F2layer variability, J. Atmos. Terr. Phys., 63 (15), 16611680.

Sagir, S., S. Karatay, R. Atici, A. Yesil and O. Ozcan (2015). The relationship between the Quasi Biennial Oscillation and Sunspot Number, Adv. Space Res., 55 (1), 106-112.

Corresponding author: Ramazan Atıc1,

Mus Alparslan University, Faculty of Education, Mus, Turkey; email: r.atici@alparslan.edu.tr.

(C) 2015 by the Istituto Nazionale di Geofisica e Vulcanologia. All rights reserved. 